\title{
Locally Recurrent Malignant Fibrous Histiocytoma: A Rare and Aggressive Genitourinary Malignancy
}

\author{
Michael Froehner $^{a} \quad$ Andreas Manseck $^{a}$ Michael Haase $^{b}$ \\ Oliver W. Hakenberg a Manfred P. Wirth ${ }^{\mathrm{a}}$ \\ Departments of aUrology and 'Pathology, University Clinic 'Carl Gustav Carus', Technical University of Dresden, \\ Germany
}

\section{Key Words}

Urological neoplasms · Sarcoma · Histiocytoma •

Local recurrence $\cdot$ Lymph node $\cdot$ Radiotherapy

\begin{abstract}
Objective: In this study, 22 cases of locally recurrent urological malignant fibrous histiocytoma were reviewed considering therapeutic options, follow-up and prognosis. Patients and Methods: In the available literature on this topic we identified 19 cases of locally recurrent genitourinary malignant fibrous histiocytoma. Three additional cases are discussed, primarily arising from the kidney, the bladder and the paratesticular region. Results: The prognosis of locally recurrent urological malignant fibrous histiocytoma was found to be extraordinarily poor. Only 2 of 22 patients have survived for longer than 3.5 years. One of them reported herein is still alive 10 years after extensive lymphatic spread accompanying the first local recurrence. In this case, late local recurrence occurred after an 8-year interval free of disease. Conclusion: Malignant fibrous histiocytoma is an unusual urological malignancy with a high rate of local recur-
\end{abstract}

\begin{tabular}{ll}
\hline KARGER & ( 1999 S. Karger AG, Basel \\
Fax +4161306 1234 & 0042-1138/99/0623-0164\$17.50/0 \\
$\begin{array}{l}\text { E-Mail karger@karger.ch } \\
\text { www.karger.com }\end{array}$ & $\begin{array}{l}\text { Accessible online at: } \\
\text { http://BioMedNet.com/karger }\end{array}$
\end{tabular}

rence. The latter is frequently accompanied by metastatic disease and unrelenting progression. Despite the poor prognosis early detection of local failure and aggressive salvage therapy might offer the chance of long-term survival in selected cases. Close and life-long follow-up is advisable for patients once treated for recurrent urological malignant fibrous histiocytoma.

\section{Introduction}

Malignant fibrous histiocytoma comprises a potpourri of poorly differentiated sarcomas with similar pathohistological, biological and clinical characteristics [1, 2]. Primary involvement of the genitourinary tract is rare with about 100 previously reported cases. Although local recurrence is common, a review of the literature yielded only 19 urological cases (table 1). We report on 3 additional cases with local recurrence after surgical treatment including 1 case with a remarkable 11-year survival after metastatic disease.
Michael Froehner, MD

Department of Urology, Universitätsklinikum 'Carl-Gustav-Carus' Technical University of Dresden, Fetscherstrasse 74 D-01307 Dresden (Germany)

Tel. +493514582447 , Fax +49 3514584333 


\section{Case Reports}

Case 1

A 72-year-old man was admitted to the hospital with fever of unknown origin, a highly accelerated erythrocyte sedimentation rate, general weakness and left flank pain. Abdominal computed tomography disclosed a $10 \times 15 \mathrm{~cm}$ left renal mass. Left radical nephrectomy was performed through a transperitoneal approach. Histopathological examination revealed a cellular neoplasm consisting of elongated, partially fusiform cells forming fascicles and occasionally displaying a storiform pattern. Extensive necrosis was present. More than 20 mitoses were observed in 10 high power fields. Between the tumor cells there was a dense lymphocellular infiltration. Immunohistological staining was positive for vimentin and $\alpha_{1}$-antitrypsin and negative for cytokeratin, desmin, actin and an epithelial marker. The histopathological diagnosis was inflammatory malignant fibrous histiocytoma. Cytokines secreted by this subtype are probably responsible for the paraneoplastic symptoms mentioned [2]. The tumor had used up the major part of the kidney and was covered by the fibrous renal capsule. There was no invasion beyond this structure. With these findings, it was not possible to define the origin (primary renal versus renal capsular) with certainty. The renal pelvis, major blood vessels and a biopsy of the tumor bed were free of tumor. Local recurrences were resected after intervals of 12, 24, 40, 60 and 66 months.
Between the operations the patient enjoyed a good quality of life. He died of a further widespread abdominal recurrence 72 months after initial nephrectomy.

\section{Case 2}

A 55-year-old man underwent transurethral resection and radical cystoprostatectomy with construction of an ileal conduit for a highgrade pleomorphic malignant fibrous histiocytoma of the bladder (fig. 1a). Microscopically, the tumor consisted of highly pleomorphic mostly polygonal cells occasionally arranged in fascicles and whirls. Bizarre Touton's giant cells were present. Immunohistochemical staining was negative for epithelial markers and positive for the histiocyte markers Ki-M1p and CD-68. The extensively necrotic tumor invaded the perivesical tissue, but the surgical margins and a biopsy of the tumor bed were free of disease. Left ureteral obstruction occurred 5 months postoperatively. Local recurrence was confirmed by CT scan and transrectal biopsy (fig. 1b, 2). The lesion was considered to be inoperable. Palliative surgery (nephrostomy, colostomy) was performed, and the patient died of tumor progression 7 months later.

\section{Case 3}

A 68-year-old man had a left orchiectomy for a paratesticular tumor at a different hospital. The histopathological diagnosis was

Table 1. Treatment and outcome of locally recurrent urological malignant fibrous histiocytoma: literature review

\begin{tabular}{|c|c|c|c|c|c|c|c|}
\hline Authors, year & Origin & Subtype & $\begin{array}{l}\text { Initial } \\
\text { treatment }\end{array}$ & $\begin{array}{l}\text { Time until } \\
\text { first local } \\
\text { recurrence }\end{array}$ & Distant failure & $\begin{array}{l}\text { Treatment } \\
\text { of local } \\
\text { recurrence }\end{array}$ & $\begin{array}{l}\text { Follow-up after } \\
\text { first local } \\
\text { recurrence }\end{array}$ \\
\hline Raghavaiah et al. [20] 1980 & Kidney & Storiform-pleom. & $\mathrm{S}$ & 9.5 months & Lung & None & 0 months (DOD) \\
\hline Singh et al. [21] 1982 & Kidney & NA & $\mathrm{S}$ & 3 months & None & None & 2 months (DOD) \\
\hline Igarashi et al. [22] 1982 & Kidney & Storiform-pleom. & $\mathrm{S}$ & 18 months & None & $\mathrm{S}$ & NA \\
\hline Adolphs et al. [23] 1982 & Kidney & NA & $\mathrm{S}$ & 22 months & None & RT, XRT & 10 months $\left(\right.$ dead $\left.^{1}\right)$ \\
\hline Srinivas et al. [24] 1984 & Kidney & Storiform-pleom. & $\mathrm{S}$ & 24 months & None & RT & 10 months (DOD) \\
\hline Scriven et al. [25] 1984 & Kidney & Storiform-pleom. & $\mathrm{S}, \mathrm{XRT}$ & 4 months & Widespread & None & 6 months (DOD) \\
\hline Hansen et al. [26] 1989 & Kidney & Storiform-pleom. & $\mathrm{S}$ & 8 months & Widespread & NA & NA \\
\hline Grignon et al. [27] 1990 & Kidney & Storiform-pleom. & $\mathrm{S}, \mathrm{CH}, \mathrm{XRT}$ & NA & NA & RT & $\mathrm{NA}\left(\mathrm{DOD}^{2}\right)$ \\
\hline Inoue et al. [28] 1990 & Kidney & Storiform-pleom. & $\mathrm{S}$ & 9 months & None & None & 5 months (DOD) \\
\hline Present case 1 & Kidney & Inflammatory & $\mathrm{S}$ & 12 months & None & $\mathrm{S}$ & 60 months (DOD) \\
\hline Goodman and Greaney [29] 1985 & Bladder & Storiform-pleom. & $\mathrm{S}$ & 5 months & Peritoneal & $\mathrm{S}$ (palliative) & NA (DOD) \\
\hline McCormick et al. [30] 1985 & Bladder & Storiform-pleom. & $\mathrm{S}$ & 3 months & Lung & None & 4 months (DOD) \\
\hline Egawa et al. [31] 1994 & Bladder & Storiform-pleom. & $\mathrm{S}$ & 4 months & None & RT & 7 months (DOD) \\
\hline Barriol et al. [32] 1997 & Bladder & Storiform-pleom. & $\mathrm{S}$ & 2 months & None & None & 0 months $\left(\right.$ dead $\left.^{3}\right)$ \\
\hline Present case 2 & Bladder & Storiform-pleom. & $\mathrm{S}$ & 5 months & None & $\mathrm{S}$ (palliative) & 7 months (DOD) \\
\hline Kumala et al. [33] 1994 & Prostate & Storiform-pleom. & $\mathrm{S}, \mathrm{XRT}$ & 3.5 years & Lung & $\mathrm{CH}$ & 2.5 years (AWD) \\
\hline Cole et al. [34] 1972 & Paratesticular & Storiform-pleom. & $\mathrm{S}$ & 12 months [14] & Lung, lymphatic & None & 3.5 years (DOD) [5] \\
\hline Williamson et al. [35] 1980 & Paratesticular & Storiform-pleom. & $\mathrm{S}$ & 18 months & Lymphatic & $\mathrm{S}, \mathrm{CH}, \mathrm{XRT}$ & NA \\
\hline \multirow[t]{2}{*}{ Adolphs et al. [23] 1982} & Paratesticular & NA & $\mathrm{S}$ & 3 years & None & $\mathrm{S}$ & 9 months (DOD) \\
\hline & Paratesticular & NA & $\mathrm{S}, \mathrm{XRT}$ & 18 months & Lung & $\mathrm{S}, \mathrm{CH}, \mathrm{XRT}$ & NA (DOD) \\
\hline Tanaka et al. [36] 1984 & Paratesticular & Storiform-pleom. & $\mathrm{S}$ & 1 year & None & None & 2 years $(A W D)$ \\
\hline Present case 3 & Paratesticular & Myxoid & $\mathrm{S}$ & 20 months & Lymphatic & S, XRT & 133 months (NED) \\
\hline
\end{tabular}

pleom. = Pleomorphic DOD = dead of disease; $\mathrm{AWD}=$ alive with disease NED = no evidence of disease; $\mathrm{NA}=$ not available;

$\mathrm{S}=$ surgery $\mathrm{CH}=$ chemotherapy; $\mathrm{XRT}$ = radiotherapy.

1 Died due to insufficiency of enteric anastomosis after extensive tumor resection.

2 Died 10 months after nephrectomy.

3 Dialysis discontinued. 

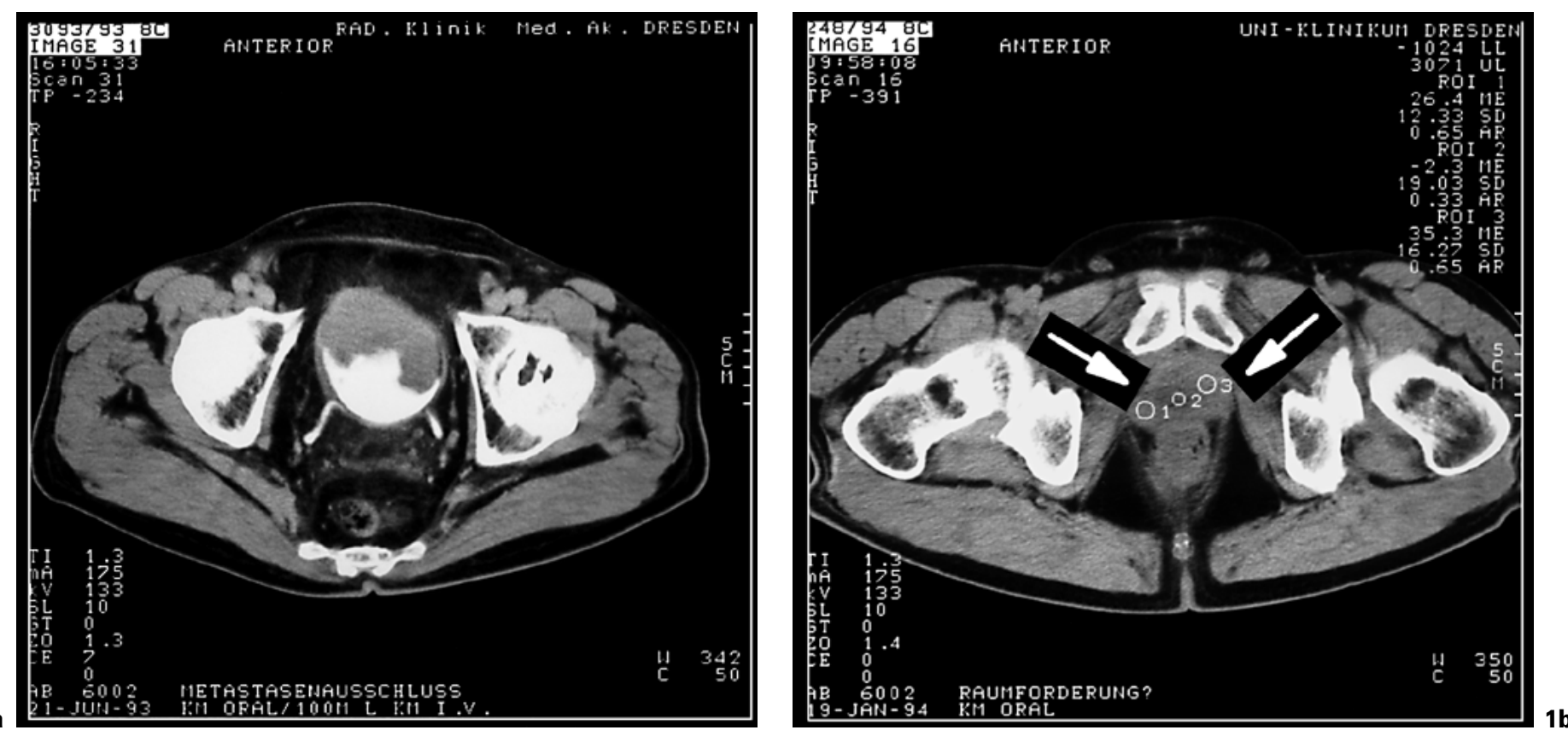

Fig. 1. Pleomorphic malignant fibrous histiocytoma of the anterior wall of the bladder (a) and local recurrence occupying the prostate bed (b, arrows), axial CT scans (case 2).

Fig. 2. Locally recurrent pleomorphic malignant fibrous histiocyto$\mathrm{ma}$ in the prostate bed, transversal endorectal 7.5-MHz ultrasound (case 2).

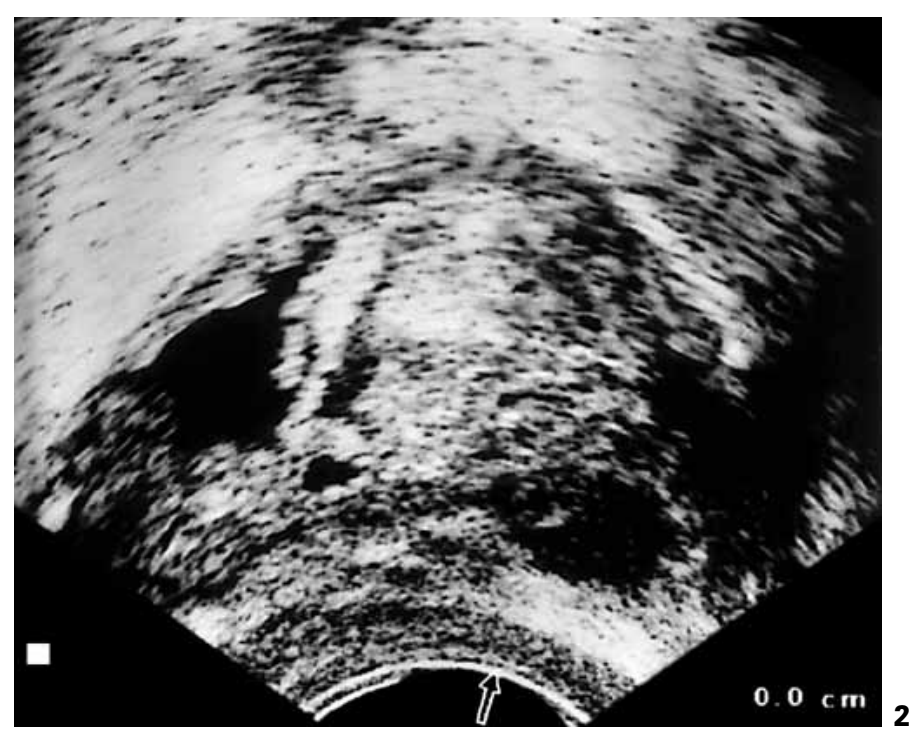

'plexiform neurofibroma with myxoid change of the stroma'. However, later reevaluation of the slides confirmed myxoid malignant fibrous histiocytoma removed with positive surgical margins. The tumor recurred locally accompanied by extensive lymphographically proven inguinal, iliac and para-aortal lymph node involvement 20 months later (fig. 3a,b). A left hemiscrotectomy was performed. Histopathology revealed a cellular neoplasm with myxoid stroma. The fusiform cells formed fascicles and whirls. The nuclei were moderately polymorphic. Uni- and multinucleated giant cells were present. The histopathologic diagnosis was recurrent myxoid malignant fibrous histiocytoma. Subsequently, the patient received a course of

$4.680 \mathrm{cGy}$ to the para-aortal region and of $5.040 \mathrm{cGy}$ to the ilial and inguinal nodes resulting in complete remission. Two more local relapses were surgically removed 15 and 24 months later. After a 96month period free of disease, a contralateral paratesticular recurrence $6 \mathrm{~cm}$ in diameter was found (fig. 4) and treated by right radical orchiectomy and complete scrotectomy. Recurrent myxoid malignant fibrous histiocytoma with scattered storiform pattern was seen microscopically (fig. 5a,b). Thirteen months later the patient was well and without evidence of recurrent disease.

$\overline{\text { Urol Int 1999;62:164-170 }}$

Froehner/Manseck/Haase/Hakenberg/ Wirth 

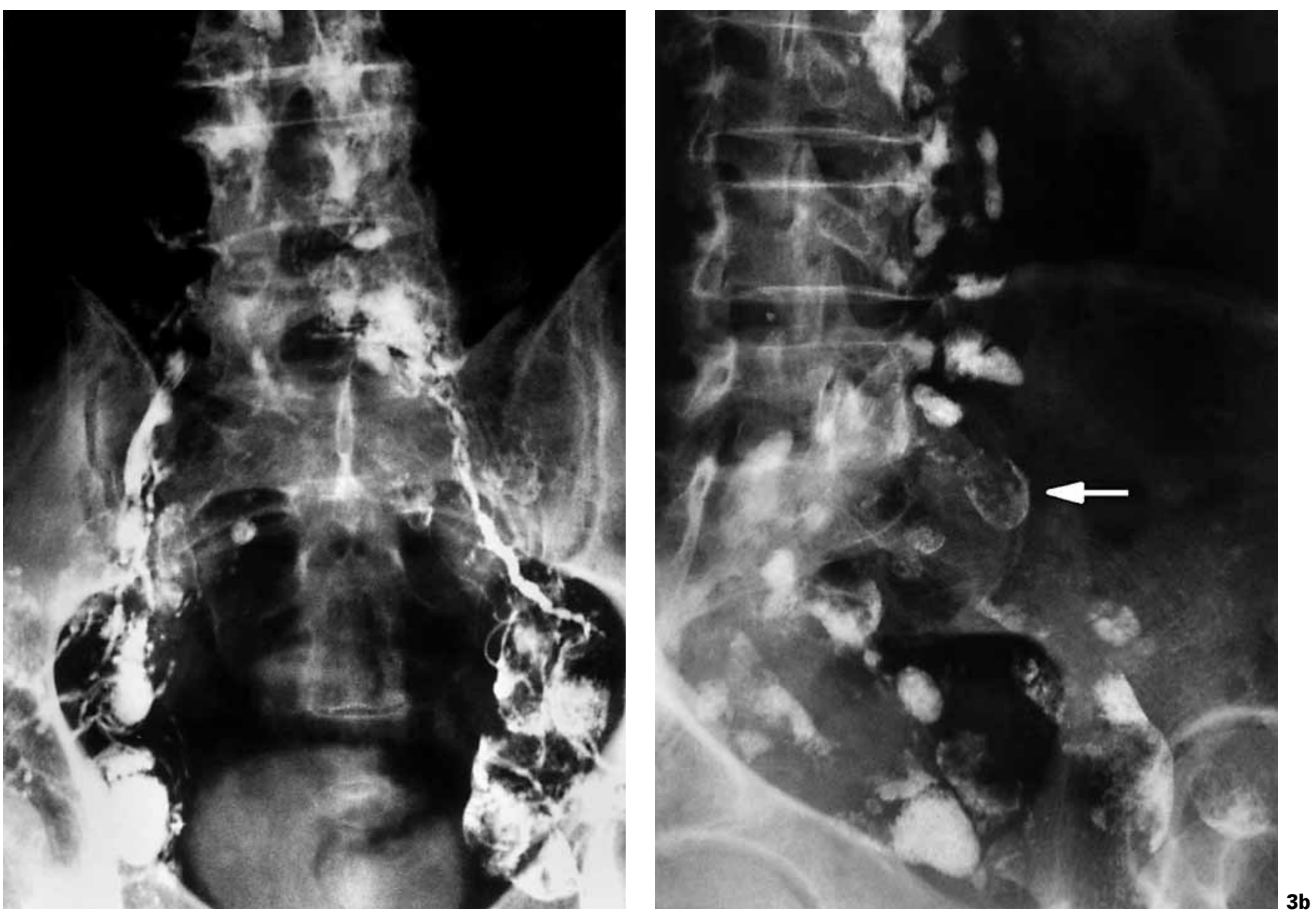

Fig. 3. Extensive bilateral lymphatic spread of a locally recurrent left-sided paratesticular myoxoid malignant fibrous histiocytoma (a) partially showing a characteristic calciform pattern of contrast medium storage (b, arrow), bipedal lymphography (case 3).

Fig. 4. Echoinhomogeneous neoplastic lesion (arrows) caudolateral to the right testicle (right), 120 months after diagnosis of lymph node failure, 7.5-MHz ultrasound (case 3).

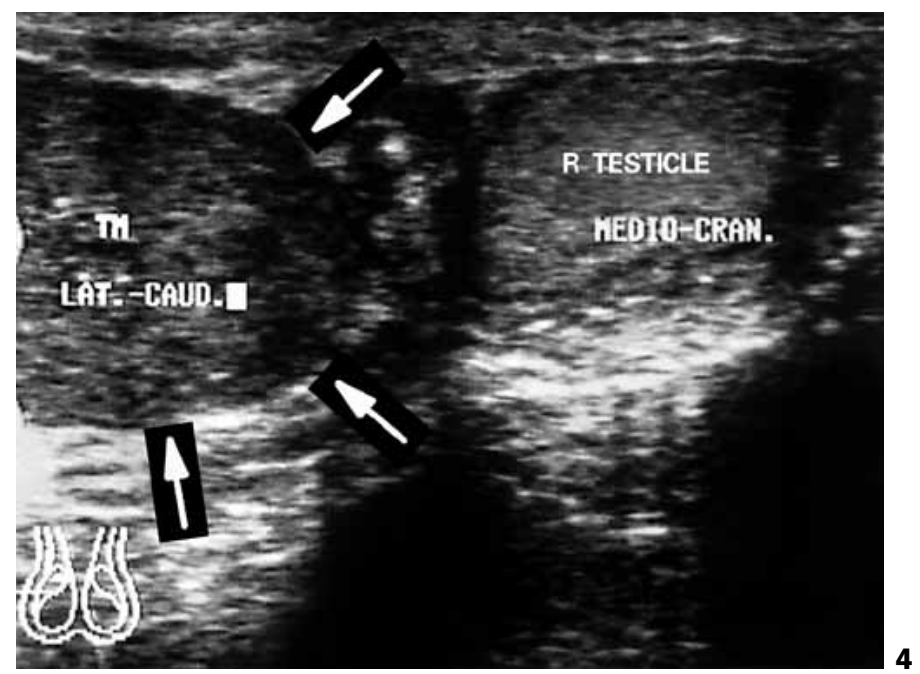

Recurrent Genitourinary Malignant

Urol Int 1999;62:164-170 

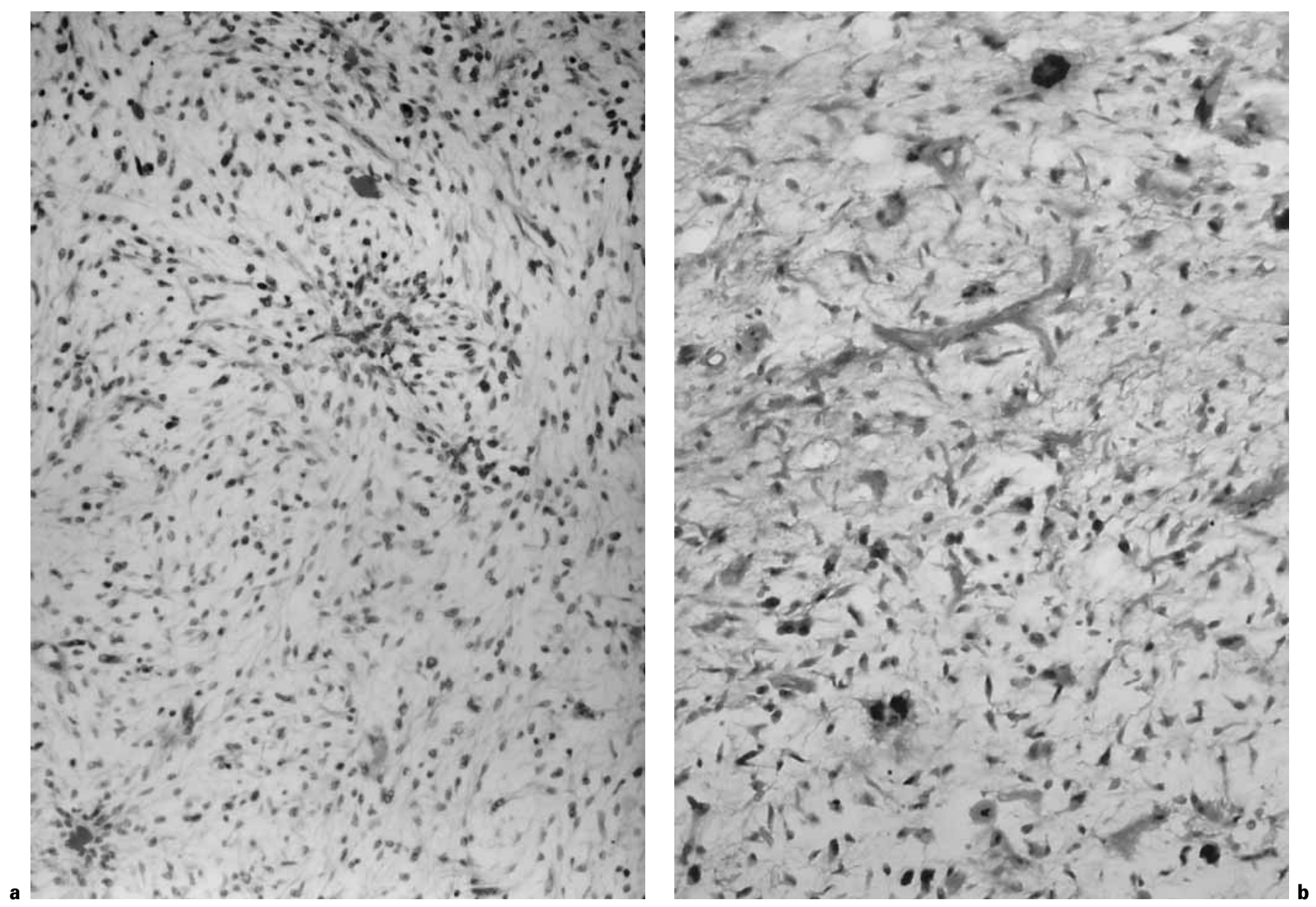

Fig. 5. Microscopic appearance of the tumor shown in figure 4 (case 3 , a, original magnification $\times 200$ ), compared with the last local recurrence 8 years ago $(\mathbf{b}$, original magnification $\times 200)$.

\section{Discussion}

Beside liposarcoma, malignant fibrous histiocytoma is one of the two most common soft tissue sarcomas in adults. The limbs, the trunk and the retroperitoneal space are predilective sites [2-7]. The histological appearance is characterized by four subtypes [2]: myxoid, storiformpleomorphic, inflammatory, and giant cell. Myxoid malignant fibrous histiocytoma shares the local but not distant aggressiveness of the other subtypes [1, 2, 4]. For this reason, Enzinger and Weiss [2] classified myxoid sybtype as grade II in contrast to the majority of malignant fibrous histiocytoma which were classified as grade III. Current grading systems classify sarcomas based on three criteria: tumor differentiation, mitosis count, and necrosis [8].
The grading is obtained by summarizing the scores for each single parameter to a final score [8].

In large studies local recurrence occurred in up to $51 \%$ after apparently complete surgical removal of malignant fibrous histiocytoma [6,7]. The retroperitoneum is an adverse site of origin with a 5-year survival rate of only $14 \%$ probably due to late diagnosis and difficult surgical accessibility $[1,6,9,10]$. Local recurrence may be accompanied by an increased malignant potential and is considered to be a risk marker for distant failure $[4,11,12]$. Cases 1 and 2 shared almost all the adverse prognostic criteria recently established in a multicenter series of 216 patients [1]: age older than 50 years; tumor size $>8 \mathrm{~cm}$, and a deeply invading high-grade nonmyxoid tumor. In case 2 , it was probably anatomically impossible to obtain 
a sufficiently wide resection due to the perivesical infiltration by this highly aggressive sarcoma known for its ability to spread along fascial planes [2] and the location deep inside the male true pelvis. In contrast to this rapidly fatal course, case 1 illustrates that an aggressive surgical reintervention might be beneficial in selected cases.

Although lymphatic spread is more common in paratesticular sarcoma than in sarcomas of other origin $[2,6$, $13,14]$, the prognosis is more favorable certainly because of earlier detection $[1,5]$. Case 3 is unique considering the long-term survival after the occurrence of extensive lymph node metastases. To our knowledge this is the first case of survival for longer than 10 years after metastatic genitourinary malignant fibrous histiocytoma reported in the available literature. Furthermore, the late local recurrence 8 years after the last tumor resection is remarkable. This case history reflects the lower malignant potential of the myxoid subtype. The favorable course in case 3 is an argument for lymph node irradiation either adjuvantly or after the occurrence of nodal failure, but little data are available [3]. The efficacy of retroperitoneal lymph node dissection or chemotherapy is limited in paratesticular malignant fibrous histiocytoma [4, 5, 9, 13-17]. In myxoid malignant fibrous histiocytoma, doxorubicin- and dacarbazine-based chemotherapy has a modest activity [18]. Recently, a meta-analysis of 14 randomized sarcoma trials demonstrated a significant advantage for adjuvant doxorubicin-based chemotherapy for local, distant and overall disease control and a trend towards prolonged overall survival [19]. However, the putative advantage is small and there is considerable toxicity [19]. Further research is needed to establish an active adjuvant chemotherapy protocol in malignant fibrous histiocytoma. Wide resection followed, if possible, by adjuvant radiotherapy is the only potentially curative treatment for primary or locally recurrent malignant fibrous histiocytoma $[1,3,4$, $9,15]$. A review of the literature demonstrates the dismal prognosis of locally recurrent urological malignant fibrous histiocytoma (table 1). Local relapse is often accompanied by distant failure, and there is no promising therapy for systemic disease. The vast majority of the recurrences arose within 3 years after surgery (table 1 ). However, after adjuvant radiotherapy for retroperitoneal sarcomas later recurrences were observed [16]. The 2 reported cases with 5- and more than 11-year survivals despite locally recurrent and (in case 3) even metastatic disease indicate that individual patients might benefit from aggressive salvage therapy. Nevertheless, definitive eradication of the tumor is very unlikely (table 1). Therefore patients once treated for locally recurrent urological malignant fibrous histiocytoma should have close and life-long follow-up.

In conclusion, malignant fibrous histiocytoma rarely arises in the genitourinary tract and possesses a high tendency towards local recurrence. The latter is frequently accompanied by metastatic spread and unrelenting progression. Despite the poor prognosis a prediction of the individual biological behavior of the locally recurrent tumor is difficult. Early detection of local failure and aggressive salvage therapy might enable long-term survival in selected cases.

\section{Acknowledgement}

The authors wish to thank Prof. J. Justus, head of the Department of Pathology, Dresden-Friedrichstadt Hospital, for kindly reviewing the slides of the primary tumor in case 3 .

\section{References}

1 Le Doussal V, Coindre JM, Leroux A, Hacene K, Terrier P, N'guyen BB, Bonichon F, Collin F, Mandard AM, Contesso G: Prognostic factors for patients with localized primary malignant fibrous histiocytoma. Cancer 1996;77: 823-830.

2 Enzinger FM, Weiss SW: Malignant fibrohistiocytotic tumors; in Enzinger FM, Weiss SW (eds): Soft Tissue Tumors, ed 3. St Louis, Mosby 1995 , pp 351-379.

3 Fagundes HM, Lai PP, Dehner LP, Perez CA, Garcia DM, Emami BN, Simpson JR, Kraybill WG, Kucick NA: Postoperative radiotherapy for malignant fibrous histiocytoma. Int J Radiat Oncol Biol Phys 1992;23:615-619.
4 Zagars GK, Mullen JR, Pollack A: Malignant fibrous histiocytoma: outcome and prognostic factors following conservation surgery and radiotherapy. Int J Radiat Oncol Biol Phys 1996; 34:983-994.

5 Glazier DB, Vates TS, Cummings KB, Pickens RL: Malignant fibrous histiocytoma of the spermatic cord. J Urol 1996;155:955-957.

6 Kearney MM, Soule EH, Ivins JC: Malignant fibrous histiocytoma. A retrospective study of 167 cases. Cancer 1980;45:167-178.

7 Weiss SW, Enzinger FM: Malignant fibrous histiocytoma: An analysis of 200 cases. Cancer 1978;41:2250-2266.
8 Guillou L, Coindre JM, Bonichon F, Bui NB, Terrier P, Collin F, Vilain MO, Mandard AM, LeDoussal V, Lerous A, Jacquemier J, Duplay H, Satre-Garau X, Costa J: Comparative study of the National Cancer Institute and French Federation of Cancer Centers Sarcoma Group grading systems in a population of 410 adult patients with soft tissue sarcoma. J Clin Oncol 1997; 15:350-362.

9 Tepper JE, Suit HD, Wood WC, Proppe KH, Harmon D, McNulty P: Radiation therapy of retroperitoneal soft tissue sarcoma. Int J Radiat Oncol Biol Phys 1984;10:825-830. 
10 Zornig C, Weh HJ, Krull A, Schwarz R, Dieckman J, Rehpenning W, Schroder S: Retroperitoneal sarcoma in a series of 51 adults. Eur J Surg Oncol 1992;18:475-480.

11 Kuratsu S, Ohsawa M, Naka N, Myoui A, Tomita Y, Uchida A, Ono K, Aozasa K: Usefulness of argyrophilic nucleolar organizer staining for predicting prognosis of patients with recurrent soft tissue sarcoma. Oncology 1994;51:244-250.

12 Gustafson P: Soft tissue sarcoma. Epidemiology and prognosis in 508 patients. Acta Orthop Scand 1994;259(suppl):1-31.

13 Fagundes MA, Ziethman AL, Althausen AF, Coen JJ, Shipley WU: The management of spermatic cord sarcoma. Cancer 1996;77: 1873-1876.

14 Sclama AO, Berger BW, Sherry JM, Young JD: Malignant fibrous histiocytoma of the spermatic cord: The role of retroperitoneal lymphadenectomy in management. J Urol 1983;130:577579 .

15 Oesterling JE, Epstein JI, Brendler CB: Myxoid malignant fibrous histiocytoma of the bladder. Cancer 1990;66:1836-1842.

16 Catton CN, O’Sullivan B, Kotwall C, Cummings B, Hao Y, Fornasier V: Outcome and prognosis of retroperitoneal soft tissue sarcoma. Int J Radiat Oncol Biol Phys 1994;29: 1005-1010.

17 Casper ES, Gainor JJ, Harrison LB, Panicek DM, Haidu SI, Brennan MF: Preoperative and postoperative adjuvant combination chemotherapy for adults with high grade soft tissue sarcoma. Cancer 1994;73:1644-1651.
18 Patel SR, Plager C, Papadopoulos NE, Benjamin RS: Myxoid malignant fibrous histiocytoma: Experience with chemotherapy. Am J Clin Oncol 1995;18:528-531.

19 Sarcoma Meta-Analysis Collaboration: Adjuvant chemotherapy for localised resectable soft-tissue sarcoma of adults: Meta-analysis of individual data. Lancet 1997;350:1647-1654.

20 Raghavaiah NV, Mayer RF, Hagitt R, Soloway MS: Malignant fibrous histiocytoma of the kidney. J Urol 1980;123:951-953.

21 Singh EO, Barrett DM, Adams VI: Synchronous occurring malignant fibrous histiocytoma of the kidney with contralateral renal cell carcinoma. J Urol 1982;128:586-588.

22 Igarashi J, Asoka $\mathrm{H}$, Nogaki J, Morita $\mathrm{H}$ Okada K, Kishimoto T: Malignant fibrous histiocytoma of the renal fibrous capsule. Jpn J Clin Oncol 1982;36:1141-1144.

23 Adolphs HD, Helpap B, Koischwitz D: Retroperitoneal and inguinal manifestation of malignant fibrous histiocytoma. Urology 1982;20: 1639-1645.

24 Srinivas V, Sogani PC, Hajdu SI, Whitmore WF: Sarcomas of the kidney. J Urol 1984;132: 13-16.

25 Scriven RR, Thrasher TV, Smith DC, Steward $\mathrm{SC}$ : Primary renal malignant fibrous histiocytoma: A case report and literature review. J Urol 1984;131:948-949.

26 Hansen CP, Meinert Jensen L, Holten I: Malignant fibrous histiocytoma of the kidney. Eur Urol 1989;16:395-397.

27 Grignon DJ, Ayala AG, Ro JY, el-Naggar A, Papadopoulos NJ: Primary sarcomas of the kidney. A clinicopathologic and DNA flow cytometric study of 17 cases. Cancer 1990;65: 1611-1618.
28 Inoue $\mathrm{H}$, Okada $\mathrm{S}$, Hongo $\mathrm{Y}$, Kirime $\mathrm{S}$, Ohara $\mathrm{H}$, Takasaki N: Malignant fibrous histiocytoma arising from the renal capsule: Report of a case. Acta Urol Jpn 1990;36:45-50.

29 Goodman AJ, Greaney MG: Malignant fibrous histiocytoma of the bladder. Br J Urol 1985;57: 106-107.

30 McCormick SR, Dodds PR, Kraus PA, Lowell DM: Nonepithelial neoplasma arising within vesical diverticula. Urology 1985;25:405-408.

31 Egawa S, Uchida T, Koshiba K, Kagata Y, Iwabuchi K: Malignant fibrous histiocytoma of the bladder with focal rhabdoid tumor differentiation. J Urol 1994;151:154-156.

32 Barriol D, Lechevallier E, Ortega JC, Koutani A, Dussol B, de Fromont M, Coulange C: Histiocytofibrome malin de la vessie. A propos d'un cas. Prog Urol 1997;7:270-272.

33 Kumala RV, Sappänen JH, Vaajalahti PJ, Tammela TLJ: Malignant fibrous histiocytoma of the prostate. Scand J Urol Nephrol 1994;28: 429-431.

34 Cole AT, Straus FH, Gill WB: Malignant fibrous histiocytoma: An unusual inguinal tumor. J Urol 1972;107:1005-1007.

35 Williamson JC, Johnson JD, Lamm DL, Tio F: Malignant fibrous histiocytoma of the spermatic cord. J Urol 1980;123:785-788.

36 Tanaka T, Nobuyuki A, Ozaki Y, Matsamura Y, Ohmori H: Malignant fibrous histiocytoma originating in the left spermatic cord with a review of 14 cases in the literature. Jpn J Clin Oncol 1984;14:437-444. 